\title{
Cellulases for oligosaccharide synthesis: a preliminary study
}

\author{
F.M. Gama, M. Mota* \\ Department of Engineering Biology, Campus de Gualtar, Universidade do Minho, 4709 codex, Braga, Portugal
}

Received 8 December 1997

\begin{abstract}
Crude cellulases, cellobiohydrolase I and endoglucanase I from Trichoderma reesei, were used for preliminary analysis of the potential of cellulases for oligosaccharide synthesis. The reaction products were analysed by ionic chromatography. Synthesis activity could be detected in concentrated aqueous solutions of glucose, cellobiose, maltose and raffinose. CBH I and EG I showed similar activity, with the exception of the case where cellobiose was the substrate. In this case, CBH I originated more oligosaccharides and in higher yields. For the best case among the studied experimental conditions (enzyme: CBH I; substrate: cellubiose; temperature: $4^{\circ} \mathrm{C}$ ), yields in the order of $40 \%$ oligosaccharides were obtained. The effect of the temperature on the reaction yield and kinetics was also studied. (C) 1998 Elsevier Science Ltd. All rights reserved.
\end{abstract}

Keywords: Cellulases; Oligosaccharide; Enzymes

\section{Introduction}

The synthesis of oligosaccharides receives growing attention due to the large number of applications of these compounds, particularly in the pharmaceutical industry. Chemical synthesis is very complex and time consuming. Alternatively, by reversing the hydrolytic action of glycosidases, and by using highly regiospecific glycosyltransferases, enzymatic oligosaccharide synthesis can be performed (Nilsson, 1988). Many reports on the literature demonstrate the synthesis activity by several glycanases (Rastall et al., 1992). However, a systematic work is still to be done, particularly with purified enzymes, comprehensively analysing the specificity of the enzymes (regarding both substrates and the synthesis reaction products), the effects of water activity, solvent polarity, temperature and substrate concentration.

In this work, preliminary results on the use of cellulases for oligosaccharide synthesis in concentrated sugar solutions are shown. These enzymes are produced in nature by several bacteria and fungae. Several enzymes are necessary for an efficient breakdown of cellulose, due to the complex and heterogeneous nature of lignocellulosics (Gama et al., 1993). Cellulases are a family of glycanases which have different affinities for the $\beta-1,4$ bond, which may depend on its position on the cellulose molecule (exo/endo) and also

\footnotetext{
* Corresponding author.
}

on its microenvironment (crystallinity degree, topography, hydrophobicity, presence of other polymers). Some of these enzymes can also hydrolyse cellulose derivatives like carboxymethylcellulose and other polymers like xylan, lichenan, laminarine, $\beta$-glucan, etc. These differences in substrate preference for the hydrolytic reaction, which we aim to study.

\section{Experimental}

\subsection{Enzymes}

Two crude enzymes (CBH I and EG I), kindly provided by Primalco, were used. These enzymes are produced by recombinant strains of Trichoderma reesei. CBH I is produced by a strain with genes encoding for EG I, EG II and CBH II deleted, and EG I is produced by a strain with genes encoding for EG II, CBH I and CBH II deleted.

\subsection{Assays for the characterization of the enzymatic activity}

All the assays were conducted in $50 \mathrm{mM}, \mathrm{pH} 5.0$ citrate buffer. One unit of enzymatic activity (U) corresponds to the release of $1 \mu \mathrm{mol}$ equivalents of glucose per minute.

\subsubsection{CMCase}

An appropriate dilution of the enzyme was added to $0.5 \mathrm{ml}$ of CMC $1 \%(\mathrm{w} / \mathrm{v})$ solution, in a test tube. The 
reaction medium was then incubated for $1 \mathrm{~h}$ at $50^{\circ} \mathrm{C}$ and the reducing sugars were measured by the DNS method.

\subsubsection{FPase}

A filter paper strip of Whatman no. $1(50 \mathrm{mg})$ was suspended in $1.0 \mathrm{ml}$ of citrate buffer. After addition of the enzyme $(0.5 \mathrm{ml})$, the reaction medium was incubated for $60 \mathrm{~min}$ at $50^{\circ} \mathrm{C}$. Finally, the reducing sugars were measured by the DNS method.

\subsubsection{Xylanase}

A solution with $1 \%$ xylan (Sigma) in citrate buffer $50 \mathrm{mM}$ with $\mathrm{pH} 5.0$ was prepared, by boiling the xylan to dissolution. To $0.5 \mathrm{ml}$ of the enzyme solution $1.5 \mathrm{ml}$ of the substrate was added, and the reaction medium was incubated for $65^{\circ} \mathrm{C}$ for $30 \mathrm{~min}$. Afterwards, the reducing sugars were measured by the DNS method.

\subsection{Oligosaccharide synthesis assays}

The enzymatic assays were conducted as follows: in a reaction vial $1.5 \mathrm{ml}$ of the substrate solution and a maximum volume of $100 \mu 1$ of the enzyme (previously diafiltrated in an ultrafiltration cell from Amicon, equipped with a PM10 membrane) were mixed and allowed to remain, without agitation, for $72 \mathrm{~h}$, at different temperatures. Samples of $100 \mu \mathrm{l}$ were taken for sugar analysis, at defined stages of the reaction. These samples were adequately diluted, boiled, and then filtered through a $0.22 \mu \mathrm{m}$ filter. Finally, they were analysed by ionic chromatography, using a Carbopac PA-1 column and a PAD detector.

\section{Results and discussion}

The enzymatic activities of the Primalco enzymes on filter paper carboxymethylcellulose and xylan are shown in Table 1.

The synthesis of oligosaccharides was followed by ionic chromatography. Several sugars were tested as substrates. Highly concentrated solutions (Table 2), close to saturation, were used so that water activity could be lowered, in order to favour the synthesis reaction. Table 2 shows the type of activity (hydrolysis/synthesis) detected with CBH I and EG $\mathrm{I}$ in the presence of different sugars. As can be seen, the two enzymes display similar activities. However, CBH I produces higher amounts of oligosaccharides when

Table 1

Charactization of the enzymes

\begin{tabular}{lcccc}
\hline Enzyme & $\begin{array}{l}\text { Protein } \\
(\mathrm{mg} / \mathrm{ml})\end{array}$ & $\begin{array}{c}\text { FPase } \\
(\mathrm{FPU})\end{array}$ & $\begin{array}{l}\text { CMCase } \\
(\mathrm{U} / \mathrm{ml})\end{array}$ & $\begin{array}{l}\text { Xylanase } \\
(\mathrm{U} / \mathrm{ml})\end{array}$ \\
\hline $\begin{array}{l}\text { Primalco Biotec } \mathrm{H} \\
\text { (CBH enriched) }\end{array}$ & 41.6 & 20.4 & 2.8 & 2425 \\
$\begin{array}{l}\text { Primalco Biotec G } \\
\text { (EG enriched) }\end{array}$ & 22.7 & 11.2 & 3.9 & 4797 \\
\hline
\end{tabular}

Table 2

Hydrolytic and synthetic activities of crude enzymes with different sugars

\begin{tabular}{|c|c|c|c|c|c|}
\hline & \multirow{2}{*}{$\begin{array}{l}\text { Sugar concentration } \\
\%(w / w)\end{array}$} & \multicolumn{2}{|c|}{ Hydrolysis } & \multicolumn{2}{|c|}{ Synthesis } \\
\hline & & EG I & CBH I & EG I & CBH I \\
\hline Glucose & 41 & & & + & + \\
\hline Mannose & 45 & & & - & - \\
\hline Cellobiose & 12 & + & + & + & + \\
\hline Maltose & 41 & + & + & + & + \\
\hline Raffinose & 26 & + & + & - & - \\
\hline
\end{tabular}

cellobiose is used as substrate. It was therefore used in the following assays.

As enriched enzymes were used, instead of pure ones, the detected activity cannot be attributed entirely to a particular enzyme, the influence of side activities being unpredictable. Therefore, it remains to be confirmed whether the hydrolytic activity detected on maltose and raffinose solutions is effectively produced by the cellulases, or by side activities present in the enzymatic solutions. It must be remarked that endoglucanases (EG III and EG V), xylanases and mannanases may also be present in the enzymatic solutions. However, the detected activity can be, with reasonable degree of confidence, attributed to CBH I and EG I. As a matter of fact, these enzymes represent the major protein fraction in the enzymatic preparations (ignoring the possible existence of proteins used as stabilizers), as it is well known from the studies on the enzymatic system of the Trichoderma reesei. On the other hand, no synthesis was detected in the mannose solutions, suggesting that mannanases, if present, have low activity. Concerning xylanase, a high level of activity was detected (Table 1). However, the natural substrate of this enzyme is a polymer of xylose, and therefore cellulases are expected to be more active both on glucose and on cellobiose solutions.

The kinetics and the influence of the temperature were followed for the particular case of CBH I acting on cellobiose. Fig. 1 shows chromatograms obtained with samples
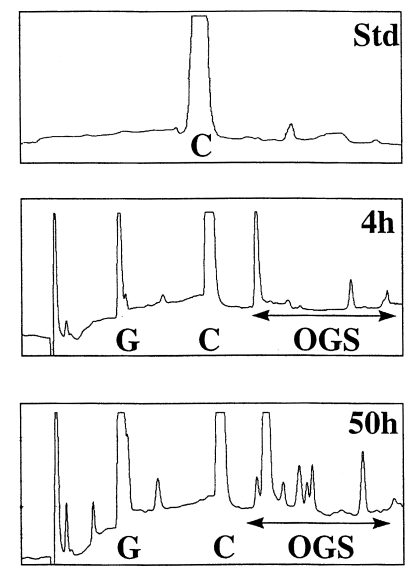

Fig. 1. Chromatographic profiles obtained with a Carbopac PA1 column for samples collected at different stages following incubation of crude $\mathrm{CBHI}$ with cellobiose at $4^{\circ} \mathrm{C}$. 


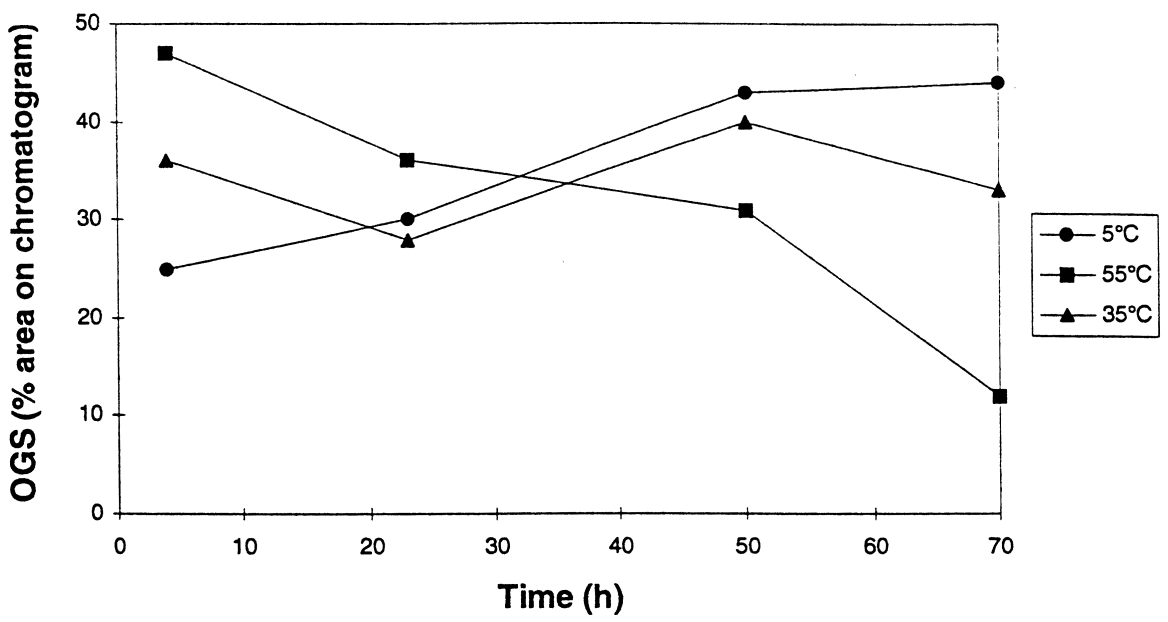

Fig. 2. Yields of the synthesis reaction as a function of temperature and reaction time.

drawn at different stages of the reaction at $4^{\circ} \mathrm{C}$. All the picks in the chromatogram, besides those of glucose and cellobiose, are products of synthesis. These correspond, quite possibly, to disaccharides with covalent bond other than $\beta-1,4$ and/or to saccharides with higher polymerization degree, since all of them have a residence time higher than cellobiose. As can be seen in Fig. 1, after $50 \mathrm{~h}$ of reaction, at least eight compounds can be clearly detected in the chromatogram, besides glucose and cellobiose, which must be produced by the synthesis activity of the enzymes. The identity of these compounds will be analysed in future work. The yields of the synthesis reaction for different temperatures and at different stages of the reaction, calculated in terms of the area ratio in the chromatograms, are presented in Fig. 2. It is clear that the oligosaccharide production can be optimized in two possible ways: by using higher temperatures and kinetically controlling the process, using short reaction periods; by using lower temperatures. In this case, higher yields can be reached at equilibrium, at the expense of longer reaction times.

The reaction yields obtained may be considered quite satisfactory, especially considering that they do not correspond to optimized conditions. Having proved that concentrated sugar solutions are interesting in the case of cellulase oligosaccharide synthesis, the possibility of reducing further the water activity must be investigated. As the temperature has a significant effect on the synthesis, the temperature dependence must be thoroughly analysed. Likewise, the effect of altering the media hidrophobicity by mixing low polarity cosolvents can also be of interest (Noritomi et al., 1996). Reactor design, and particularly the use of external circulation with selective traps for the reaction products, may also allow better yields (Ajisaka et al., 1987).

Further work requires purified enzymes, especially to allow for the comparison of the activity of EG I and CBH I. These enzymes share the main features, structural and catalytic. Both have a two domain structure, one responsible for the adsorption on the cellulose surface, the other for the catalytic activity. Both hydrolyse $\beta-1,4$ bonds. However, they have different affinities for the position of the covalent bond in the cellulose molecule, the CBH I acting "preferentially" as an exoglucanase and the EG I as an endoglucanase. Moreover, as opposed to CBH I, EG I can hydrolyse xylan and $\beta$-glucan. CBH I has a catalytic domain which is formed by a tunnel $40 \AA$ long. In the case of CBH II, the catalytic domain is only $20 \AA$ longer. In the case of EGs, it seems to be even smaller, since these are smaller enzymes, but no crystallographic data is available at the moment. Possibly, the size and also the form of the catalytic domain are on the origin of the affinity differences of the several cellulases. Further analysis of the effect of different catalytic site geometries on the enzymatic synthesis properties may lead to interesting conclusions.

\section{References}

Ajisaka, K., Nishida, H., \& Fujimoto, H. (1987). Use of an activated carbon column for the synthesis of disaccharides by use of a reversed hydrolysis activity of a $\beta$-galactosidase. Biotechnol. Lett., 9, 387-392.

Gama, F.M., Faro, C.J., Teixeira, J.A., \& Moto, M. (1993). New methodology for the characterization of endoglucanase activity and its application on the Trichoderma longibrachiatum cellulolytic complex. Enzyme Microb. Technol., 15, 57-61.

Nilsson, K.I. (1988). Enzymatic synthesis of oligosaccharides. TIBTECH., $6,256-264$.

Noritomi, H., Almarsson, O., Barletta, G.L., \& Klibanov, A.M. (1996). The influence of the mode of enzyme preparation on enzymatic enantioselectivity in organic solvents and its temperature dependence. Biotechnol. Bioengng, 51, 95-99.

Rastall, R.A., Rees, N.H., Wait, R., Adlard, M.W., \& Bucke, C. (1992). $\alpha$-Mannosidase-catalysed synthesis of novel manno-, lyxo-, and heteromanno-oligosaccharides: a comparison of kinetically and thermodynamically mediated approaches. Enzyme Microb. Technol., 14, 5357. 